\title{
Entrelacs
}

Cinéma et audiovisuel

HS | 2012

Le post-humain et les enjeux du sujet

\section{Le corps photographié se souvient du futur}

\section{Céline Henry}

\section{OpenEdition}

\section{Journals}

Édition électronique

URL : http://journals.openedition.org/entrelacs/302

DOI : 10.4000/entrelacs.302

ISSN : 2261-5482

Éditeur

Éditions Téraèdre

Édition imprimée

Date de publication : 2 février 2012

ISBN : 978-2296567177

ISSN : 1266-7188

\section{Référence électronique}

Céline Henry, «Le corps photographié se souvient du futur », Entrelacs [En ligne], HS | 2012, mis en ligne le 01 août 2012, consulté le 19 avril 2019. URL : http://journals.openedition.org/entrelacs/302 ; DOI : 10.4000/entrelacs.302

Ce document a été généré automatiquement le 19 avril 2019.

Tous droits réservés 


\title{
Le corps photographié se souvient du futur
}

\author{
Céline Henry
}

1 Le texte complet de cet article est publié dans l'ouvrage :

Post humain et les enjeux du sujet

Editeur : L'HARMATTAN (2 février 2012)

Collection Ouverture Philosophique

ISBN-10 : 2296567177

ISBN-13 : 978-2296567177 
Aziz et Cucher, John, 1995

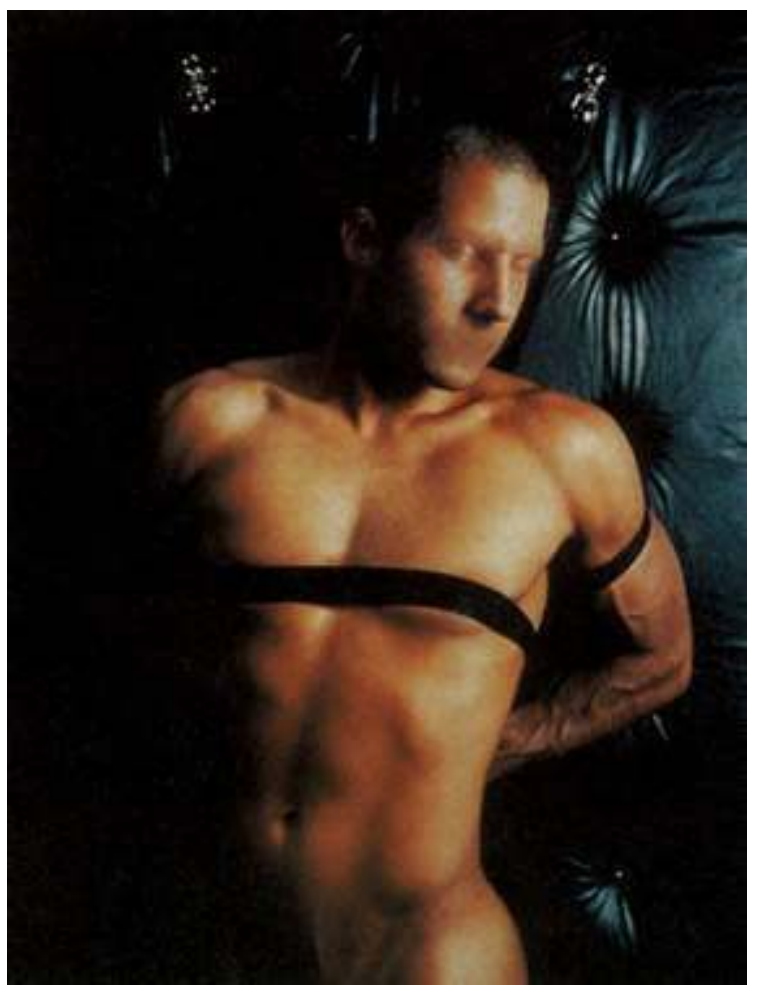

LawickMüller, Chios, PerfectlySuperNatural, 1999
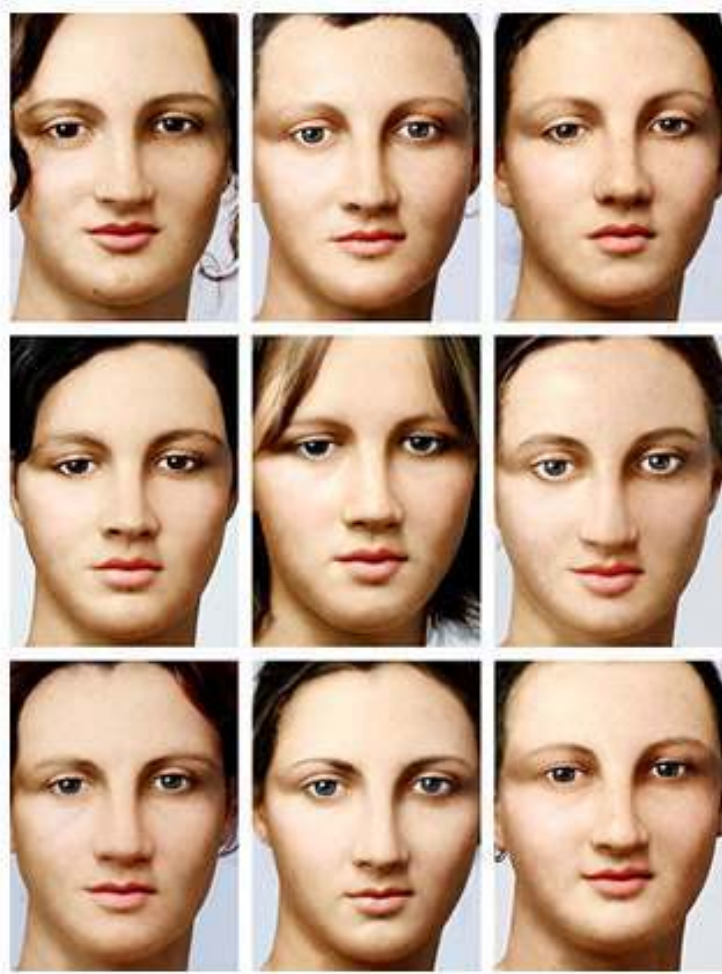


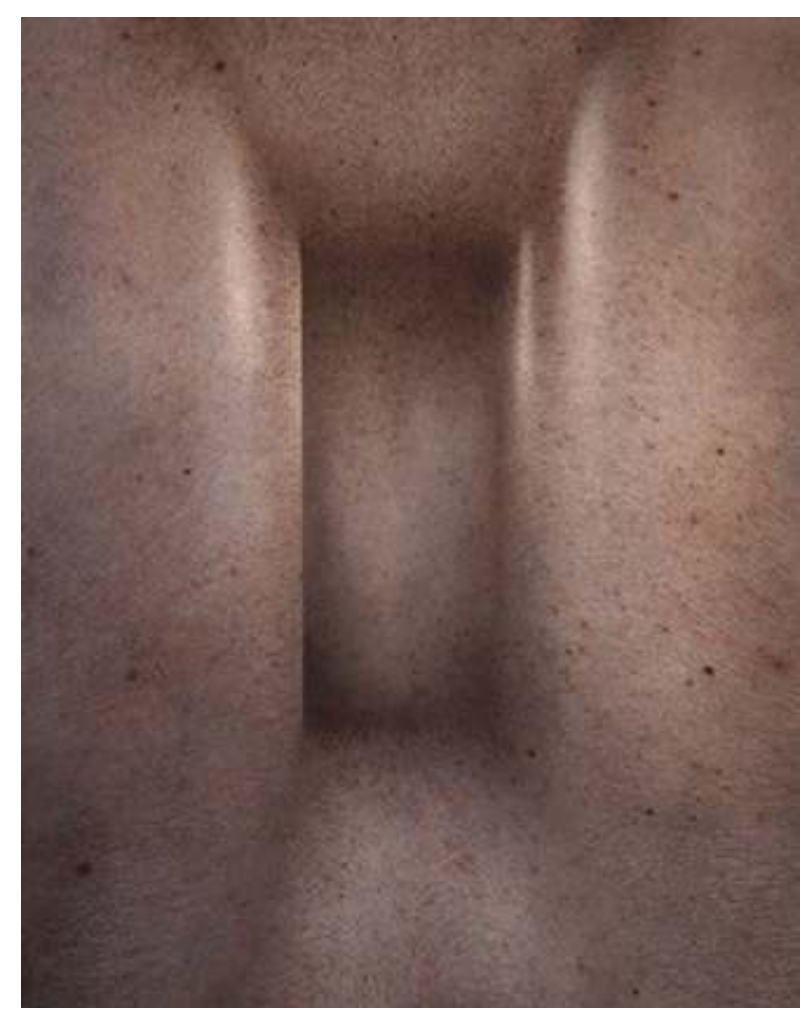

Dans cette image troublante d'Aziz et Cucher, notre corps, notre peau, semblent cloisonner le labyrinthe de notre solitude, et en même temps ouvre sur un horizon que nous pressentons, sans le voir. Le désir d'y accéder nous fait avancer. Il reste donc à espérer que jamais la réalité ne rattrape le rêve, que la maîtrise et la perfection, du corps comme de l'image, se trouble toujours de l'imprévu, de l'accidentel, et du doute.

\section{RÉSUMÉS}

A l'ère du post-humain, le corps s'exhibe à nouveau sur la scène artistique et éprouve ses capacités plastiques. De l'art corporel des années soixante à l'art post-humain, les enjeux diffèrent en même temps que les outils de monstration du corps évoluent. La photographie s'hybride au même titre que le corps, en s'alliant aux technologies informatiques.

Ce faisant, elle révèle des tensions au sein de ces hybridations : l'intérieur s'extériorise, la nudité dévoile l'asexualité, le corps obsolète devient matière première. Ces tensions soulèvent la question de l'origine et de la disparition, non plus du corps, mais de l'humain.

En jouant de ses capacités analogiques tout en s'ouvrant au virtuel, la photographie oscille entre documentaire et fiction ; elle témoigne d'un devenir, d'une possibilité. Alors qu'elle était trace, relique, elle se porte au-devant du corps, l'anticipe et le distancie. Il est donc toujours question d'écart dans la relation entre le corps voyant et son image. Comment l'artiste répond à cet écart? 
AUTEUR

CÉLINE HENRY

Doctorante en Arts Plastiques, Université de Toulouse-Le Mirail 